\title{
IMPACT OF ELECTRONIC INFORMATION RESOURCES ON USERS OF SELECTED ENGINEERING COLLEGE LIBRARIES OF ODISHA, INDIA
}

\author{
Ashutosh Padhi \\ Research Scholar, Dept. of Library and Information Science, \\ Utkal University, Bhubameswar, Odisha, India \\ Dr. Bulu Moharana \\ Professor, Dept. of Library and Information Science, \\ Sambalpur University, Odisha, India
}

\begin{abstract}
The present study explores the impact of electronic information resources among the users of engineering college libraries. This study collected all required information through a survey method by administering a structured questionnaire. A total of 549 users from 34 engineering colleges participated in the study. The major findings of the current study shows that, due to the emergence of e resources, more than 80 per cent users are keeping themselves up to date with information. The learning-teaching efficiency of the student as well as faculty has increased due transition from print to electronic information resources. Similarly, 74 per cent users said, access to amount of information sources, efficiency in accomplishment of academic assignment and research \& publication activities have increased due to transformation from print to electronic resources. According to most of the users, all types of e-resources, specifically E-Journals and E-Books have a high impact on the teaching and learning process. The study results also reveal that, 82 per cent prefer the electronic resources due to its easy accessibility and 64 per cent prefer the print resources because it is easy to read. Again, more than 80 per cent users agree that, electronic resource give huge amount of information and easy to manage by adding book marks and notes.
\end{abstract}

Key words: Electronic Information Resources, Engineering College libraries, Impact of Electronic Resources, Teaching and learning process, Faculty, Student

Cite this Article: Ashutosh Padhi and Dr. Bulu Moharana, Impact of Electronic Information Resources on Users of Selected Engineering College Libraries of Odisha, India. International Journal of Library \& Information Science, 7(2), 2018, pp. 30-38. http://iaeme.com/Home/issue/IJLIS?Volume=7\&Issue=2 


\section{INTRODUCTION}

The Twenty-first century witnessed enormous advancements in the fields of science and technology; there is hardly any discipline which is not influenced by such modern innovations (Vanaja, 2017, p.143). The world of libraries is facing tremendous changes due to the developments in information technology and abundance increase of information. Libraries have transformed into digital and virtual libraries where books, journals and magazines have changed into e-books, e-journals, and e-magazines. This has increased the global dissemination of information (Abinew \& Vuda, 2013, pp. 903-910).Electronic resources are some of the most important activities of libraries and they provide excellent opportunities to access scholarly information, which were previously the geographical constraints (Santhi \& Jeyachitra, 2014, p.235).The veritable explosion of networked information and the relative ubiquity of computer access have made it possible for the academic community to find and receive a significant amount of information without going to the library (Hiller,2002,pp. 134139).The present electronic environment has altered the conduct of teaching and learning by allowing the Users of library a wide range of opportunity for accessing accurate and timely information.(Kumar \& Bhandi,2016.p.21).E-Resources play a vital role in the field of engineering studies and the user community is becoming more and more familiar with them to access very regularly.(Badhusa \& Natarajan, 2014, p.1).As libraries are developing a large web presence, issues regarding the utility, accessibility and usage of their networked resources and services are gaining critical importance (Pulm et. al ,2010,p.184). So the transition of information resources from print to electronic medium has left an impact on library and users' perception as well (tenopir,2003, p.1).

\section{REVIEW OF LITERATURE}

The literature published directly related to the present study have been reviewed.

Sahu and Basa (2009) explored the usage pattern of the existing electronic information resources and services by the students and found that majority of the students frequently access the subscribed e resources in the library and give utmost preference to internet access for their needs. Kaur and Verma (2009) studied the emergent e-libraries/e-journals in IIT, Delhi using the questionnaire method and were of opinion that the facilities of updated eresources to be provided depending upon needs of the users. Sahu and Mohapatra (2011) enquired present status of existing digital library facility in BPUT affiliated engineering colleges in Orissa established up to 2008.Sahu (2013) surveyed different skill aspects of staff working in engineering college libraries of Orissa to identify their recent job description, day to day functioning and new knowledge required to sustain in the digital era. Mendhe,Kamble and Taksande (2013) reported the intricacies of commonly accepted data base (from $e$ resources) used by the learned faculties of western India. Das and Choudhury (2014) ascertained the nature of management of collection in the web scenario and in selected university libraries of Odisha,. Sarvanan and Esmail (2015) studied on decadal shift in adaptation of usage of library by the engineering studies from primitive traditional to recent eresources Lewis (2016) endorsed the importance laid by the students/scholars on e-resources and investigated the usage and effect of AICTE and DELNET subscribed e resources in engineering colleges of two different districts of Karnataka state. Khan et al. ( 2017) examined the impact of digital library resources (DLR'S) on academic and engineering research and found significant correlation between the purpose and frequency of their use in Pakistan. Aravazhi (2017) described different types of e resources and their impact on library. The study revealed the advantages of space, time, multidimensional and easy to search aspects of electronic environment. Srivastava and Kumar (2018) studied the titles of 
the high impact factor journals, the numbers of down loads of a material science package, its impact on users .

It is revealed that no such studies have been conducted on impact of electronic resources on users of engineering college libraries of Orissa so far.

\section{STATEMENT OF THE PROBLEM}

Despite Engineering college libraries belong to academic library stream, its collection assembled, has been aimed to meet the needs of a particular group of users; limited to a single subject or group of subject or a single format or group of formats. The library is assigned the mission of acquiring, organizing and providing information and knowledge, recording in print and non print form so as to further the goals of its parent organization.

Electronic services are attracting reader attention in today's network environment. This changing scenario in engineering college library environment has arisen to meet the increased information need of the users with adequate access to e-resources backed with the traditional print resources. Electronic resources appear to pose new challenges before the users of library and information science in respect of providing full text access to scholarly publications both in print and electronic versions. The present research, therefore tries to explore the types of electronic information resources; users opinion about it and impact on teaching-learning process.

\section{OBJECTIVES OF THE STUDY}

- To examine the impact of electronic resources on information seeking behavior and teaching and learning process of library users.

- To know the perception of students and faculties on electronic information resources.

\section{5, SCOPE AND LIMITATION}

The scope and coverage of the proposed study extends to 34 major engineering college libraries established up to 2002. However, like any empirical study, the present investigation is characterized by following limitations.

- The scope of the study is geographically limited to the state of Orissa.

- There are different types of technical and non technical institutes in Orissa, but this research is limited to engineering colleges only.

- The study is limited to only electronic information resources and no other aspect of the libraries are investigated.

- The study has been carried out in the following engineering colleges.

\begin{tabular}{|l|c|c|c|}
\hline \multicolumn{1}{|c|}{ Name of the College } & Code & Address & $\begin{array}{c}\text { Year of } \\
\text { establishment }\end{array}$ \\
\hline Ajay Binay Institute of Technology & ABIT & Cuttack & 1998 \\
\hline Balasore College of Engineering \& Technology & BCET & Balasore & 2001 \\
\hline Bhadrak Institute of Engineering and Technology & BIET & Bhadrak & 1982 \\
\hline College of Engineering & CEB & Bhubaneswar & 1999 \\
\hline College of Engineering and Technolgy & CET & Bhubaneswar & 1981 \\
\hline CV Raman College of Engineering & CVRCE & Bhubaneswar & 1997 \\
\hline Dhaneswar Rath Institute of Engineering and Management & $\begin{array}{c}\text { DRIEM } \\
\text { S }\end{array}$ & Cuttack & 1999 \\
\hline Eastern Academy of Science \& Technology & EAST & Bhubaneswar & 2001 \\
\hline GhanashyamHemalata Institute of Technology \& Management & GHITM & Puri & 1997 \\
\hline
\end{tabular}


Impact of Electronic Information Resources on Users of Selected Engineering College Libraries of Odisha, India

\begin{tabular}{|l|c|c|c|}
\hline Gandhi Institute of Advanced Computer \& Research & GIACR & Rayagada & 2000 \\
\hline Gandhi Institute of Engineering and Technology & GIET & Gunupur & 1997 \\
\hline Gopal Krishna College of Engineering \& Technology & GKCET & Jeypur & 1999 \\
\hline Indira Gandhi Institute of Technology & IGIT & Saranga & 1982 \\
\hline Jagannath Institute of Engineering and Technology & JIET & Cuttack & 1996 \\
\hline Jagannath Institute of Technology and Management & JITM & Paralakhemundi & 1997 \\
\hline Krupajal Engineering College & KEC & Bhubaneswar & 1999 \\
\hline Kalinga Institute of Industrial Technology & KIIT & Bhubaneswar & 1997 \\
\hline Koustuv Institute of Self Domain & KISD & Bhubaneswar & 2001 \\
\hline Konark Institute of Science \& Technology & KIST & Jatni & 2001 \\
\hline Mahavir Institute of Engineering and Technology & MIET & Bhubaneswar & 2001 \\
\hline Majhighariani Institute of Technology \& Science & MITS & Rayagada & 1999 \\
\hline National Institute of Science and Technology & NIST & Berhampur & 1996 \\
\hline National Institute of Technology & NIT & Rourkela & 1961 \\
\hline Orissa Engineering College & OEC & Jatni & 1986 \\
\hline Padmanava College of Engineering & PCE & Rourkela & 1999 \\
\hline Purushottam Institute of Engineering & PIET & Rourkela & 1999 \\
\hline Padmashree Krutartha Acharya College of Engineering & PKACE & Bargarh & 2002 \\
\hline Roland Institute of Technology & RIT & Berhampur & 2000 \\
\hline Samanta Chandrasekhar Institute of Technology \& Management & SCITM & Semiliguda & 2001 \\
\hline Seemant Engineering College & SEC & Baripada & 1997 \\
\hline Synergy Institute of Engineering and Technology & SIET & Dhenkanal & 1999 \\
\hline Silicon Institute of Technolgy & SIT & Bhubaneswar & 2001 \\
\hline Sanjay Memorial Institute of Technology & SMIT & Berhampur & 2001 \\
\hline Veer Surendra Sai University of Technology & VSSUT & Burla & 1956 \\
\hline
\end{tabular}

\section{METHODOLOGY}

A complete quantitative survey method was followed to gather required data by administering a structured questionnaire among the library users which contains information about users' profile, opinion about e-resources and it's impact on teaching and learning process. With a view to cover more than 500 user sample, 20 users including both students and faculties were approached in each of the 35 selected colleges. A total of 700 user questionnaires were distributed. Despite continuous follow-up and visit to the colleges, 549 filled-in questionnaires could be collected with a response rate of 78 per cent.

\section{Data Analysis and Interpretation}

The users who have participated in the study have diverse background characteristics consisting of different gender, ages, departments, students and faculties. It is found that (Table-1), about 73 per cent male and 27 per cent female users have participated in the current study. More than half of the users are less than 26 years and about 36 per cent are more than 30 years. Of all the departments, 21 per cent belong to CSE, followed by Basic Science and Humanities (19 per cent), Mechanical (18 per cent), Civil (12 per cent) and Electronics and Communication Engineering (ECE) (11 per cent). Users from other departments like Chemical, Electrical Engineering (EE), Electrical and Electronic Engineering (EEE) and IT range from 1 to 9 per cent. Among all the users who participated in the study, majority (42 per cent) are UG students. Only 9 percent are PG students and 1 per cent are PhD scholars. As very few colleges have option for taking $\mathrm{PhD}$ students, only 4 such users have participated in the study. The remaining 48 per cent users are faculties consisting of professors, associate professors and assistant professors. 
Table 1 Profile of the library users

\begin{tabular}{|l|c|c|}
\hline \multicolumn{1}{|c|}{$\begin{array}{c}\text { Background characteristics } \\
\text { of the users }\end{array}$} & N & \% \\
\hline Gender & & \\
\hline Male & 400 & 72.9 \\
\hline Female & 149 & 27.1 \\
\hline Age & & \\
\hline$\leq 20$ years & 123 & 22.4 \\
\hline $21-25$ years & 160 & 29.1 \\
\hline $26-30$ years & 71 & 12.9 \\
\hline$\geq 31$ years & 195 & 35.5 \\
\hline Department & & \\
\hline Chemical & 4 & 0.7 \\
\hline Civil & 65 & 11.8 \\
\hline CSE & 115 & 20.9 \\
\hline ECE & 62 & 11.3 \\
\hline EE & 51 & 9.3 \\
\hline EEE & 34 & 6.2 \\
\hline IT & 14 & 2.6 \\
\hline Mechanical & 98 & 17.9 \\
\hline Mining & 0 & 0.0 \\
\hline Other (Basic Sc. and Humanities) & 106 & 19.3 \\
\hline Type of user & & \\
\hline Faculty (Prof) & 48 & 8.7 \\
\hline Faculty (Asso. Prof) & 39 & 7.1 \\
\hline Faculty (Asst. Prof) & 173 & 31.5 \\
\hline PhD Scholar & 4 & 0.7 \\
\hline Student (PG) & 50 & 9.1 \\
\hline Student (UG) & 229 & 41.7 \\
\hline Others & 6 & 1.1 \\
\hline
\end{tabular}

The users were asked questions about their opinion regarding transition from print to electronic medium of information resources. It is evident form Figure-1 that, for more than 80 per cent

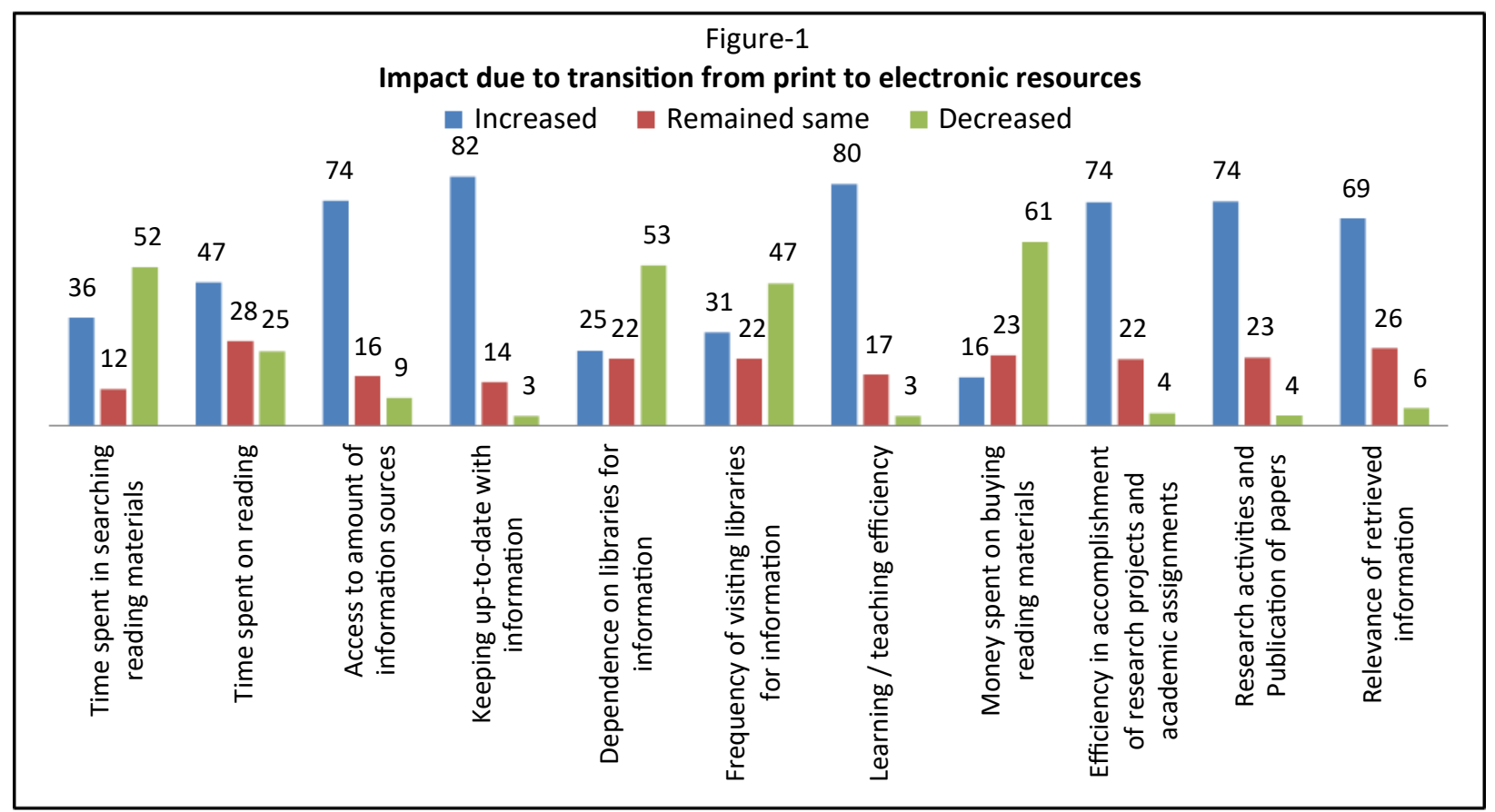


Users, keeping up to date with information and learning-teaching efficiency has increased due transition from print to electronic information resources. Similarly, 74 per cent users said, access to amount of information sources, efficiency in accomplishment of academic assignment and research \& publication activities has increased due to transformation from print to electronic resources. About 69 per cent users said that retrieval of information has increased due to introduction of e-resources. In the contrary, due to electronic resources, money spent on buying reading materials has been decreased. This is stated by 61 per cent users. Accordingly, more than half of the users have the opinion that, due to e-resources, their time spent in searching reading materials and dependency on the library has decreased. Again, 47 per cent said that, e-resource has decreased their frequency to visit library. However the overall analysis shows a positive impact of electronic resources on the users where they easily and quickly search requires resource materials. This in result seems to be improved their learning process and keeping up to date.

Table 2 Impact of e-resources on teaching and learning process

\begin{tabular}{|l|c|c|c|c|c|c|}
\hline \multicolumn{1}{|c|}{ Types of E-resources } & \multicolumn{2}{c|}{ High } & \multicolumn{2}{c|}{ Moderate } & \multicolumn{2}{c|}{ Low } \\
\cline { 2 - 8 } & $\mathbf{N}$ & $\mathbf{\%}$ & $\mathbf{N}$ & $\mathbf{\%}$ & $\mathbf{N}$ & $\mathbf{\%}$ \\
\hline E-Books & 407 & 74.1 & 130 & 23.7 & 12 & 2.2 \\
\hline E-Journals & 434 & 79.1 & 97 & 17.7 & 18 & 3.3 \\
\hline E-Databases & 288 & 52.5 & 200 & 36.4 & 61 & 11.1 \\
\hline E-Theses and dissertation & 269 & 49.0 & 165 & 30.1 & 115 & 20.9 \\
\hline E-Newspapers & 307 & 55.9 & 155 & 28.2 & 87 & 15.8 \\
\hline
\end{tabular}

Table-2 depicts users response about the impact of different types of e-resources on teaching and learning process show that, for most of the users, all types of e-resources have a high impact on the teaching and learning process. Specifically, E-Journals and E-Books have high impact, which is said by 79 and 74 per cent of the users respectively. More than half of the users said, E-Newspaper and E-Databases have high impact on the teaching and learning process.

Table 3 User's preference of different features of information sources

\begin{tabular}{|l|c|c|c|c|}
\hline \multirow{2}{*}{ Features of E-Resources } & \multicolumn{2}{|c|}{ Print } & \multicolumn{2}{c|}{ Electronic } \\
\cline { 2 - 5 } & $\mathbf{N}$ & $\mathbf{\%}$ & $\mathbf{N}$ & $\mathbf{\%}$ \\
\hline Authenticity of information & 278 & 50.6 & 271 & 49.4 \\
\hline Ease of access & 101 & 18.4 & 448 & 81.6 \\
\hline Ease of reading & 351 & 63.9 & 198 & 36.1 \\
\hline Making a personal collection & 197 & 35.9 & 352 & 64.1 \\
\hline
\end{tabular}

Results regarding user's preference for different features of information sources highlighted in the above table. It shows, 82 per cent prefer the electronic resources due to its easy accessibility, while 64 per cent prefer the print resources because it is easy to read. However for authenticity of information, almost same proportion of users prefer print as well as electronic resources. Thus, it clarifies that users prefer print resources due to some features and electronic resources due to some other features. 


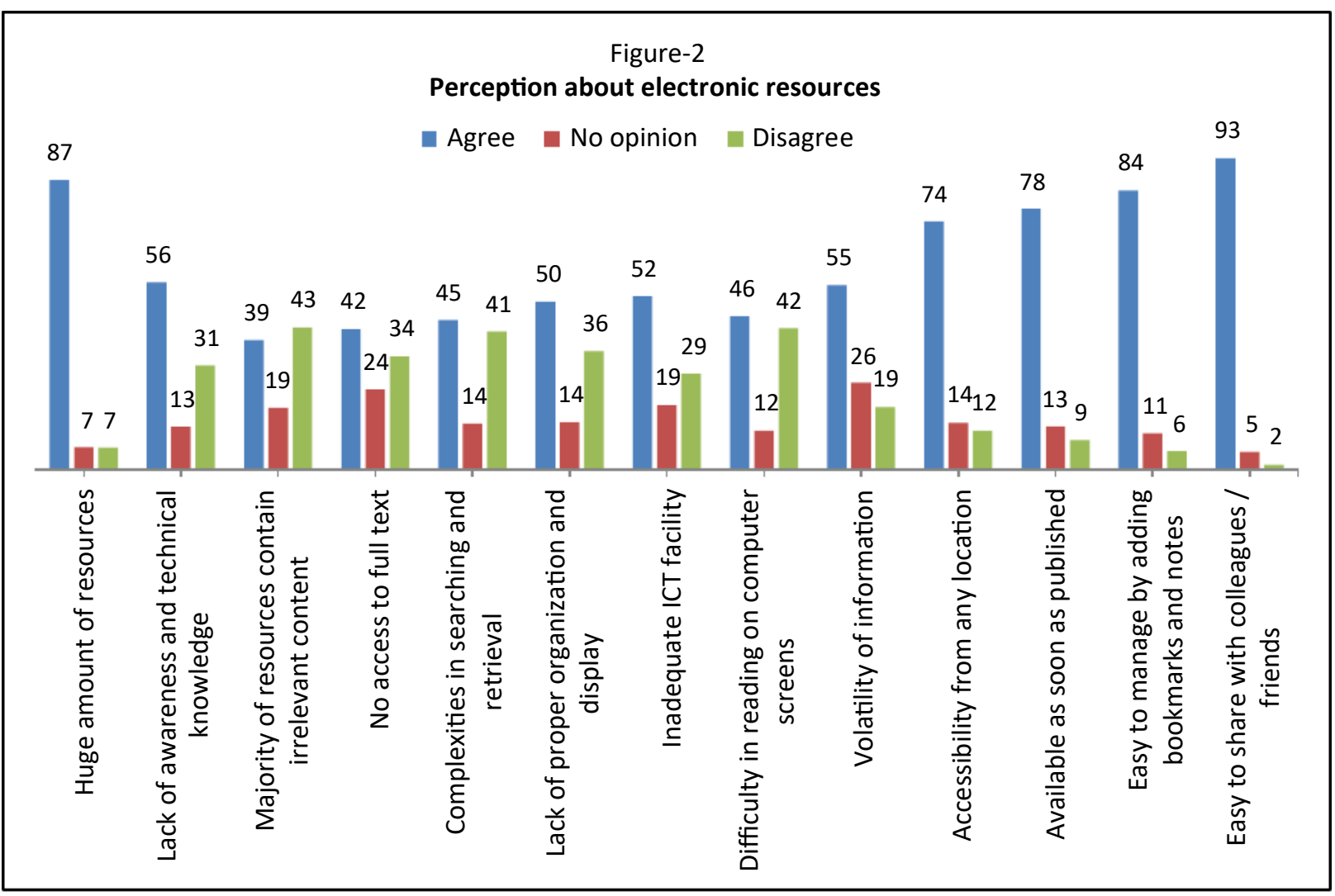

Users' perception regarding electronic information resource varies significantly from one aspect to the other as shown in Figure-2. The most agreed insight (93 per cent) is, e-resources are easy to share with colleagues and friends. More than 80 per cent users agree that, such types of resource are huge in amount and easy to manage by adding book marks and notes. Similarly more than 70 per cent agree to the fact that, e-resources are accessible from any location and available as soon as published. However about 45 per cent users found that, eresources are difficult to read and have complexity in searching and retrieval. About 43 per cent disagree that, majority of e-resources contain irrelevant content and 42 per cent said, it has no access to full text.

\section{CONCLUSIONS}

Undoubtedly, electronic resources have become essential in today's environment where digitization of information is given utmost priority. In this context electronic resources are preferred over the print resources by students and faculties for various reasons. Electronic resources have the advantage of keeping the user up to date, easy accessibility, knowing wide variety of information, easy storage, improved teaching and learning process, which attract most of the users. Additionally, the expenses made for it is very minimal compared to print resources. Thus it is worth to invest more resources to improve subscription of e-resources and widen its accessibility. This is expected to give a good mileage in the information seeking and dissemination behavior among the students and faculties of engineering colleges.

\section{REFERENCES}

[1] Aravazhi, M. S. (2017). Impact of electronic information sources on library system: a conceptual analysis, EPRA International Journal of Economic and Business Review, 5 (11),32-34. 
Impact of Electronic Information Resources on Users of Selected Engineering College Libraries of Odisha, India

[2] Lewis, F. (2016). Use and Impact of AICTE electronic Resources and DELNET in the engineering College Libraries of Dakshina Kannada and Udupi Districts : A Comparative Study. SRELS journal of Information Management,53(3). Retrieved from http://www.informaticsjournals.com/index.php/srels/article/view/6397

[3] Khan, A., Ahmed, S., Khan, A., \& Khan, G. (2017).The Impact of digital Resources usage on Engineering Research Productivity : an Empirical Evidences from Pakistan. Collection Building,36(2),37-44. Retrieved from https://doi.org/10.1108/CB-10-2016-0027

[4] Kaur, B., \& Verma, R. (2009). Use and impact of Electronic journals in the Indian Institute of Technology, Delhi, India. The Electronic Library,27(4),611-622.Retrieved from http://dx.doi.org/10.1108/02640470910979570

[5] Mendhe, R, M., Kamble, A. S., \& Taksande, P. G. (2013). Use and Impact of IEEE, ASME and

[6] DELNET:A Case Study With Special Reference to Faculty Members of Engineering Colleges Affiliated to North Maharashtra University, Jalgaon Maharashtra, LIBRARY HERALD,51(2),156-167.Retrieved from www.indianjournals.com

[7] Saravanan, M., \& Mohammed, E. (2015). Impact of Electronic Information Seeking Behavior of users of selected Engineering Colleges Affiliated to Anna University in Thiruvallur District: A Case Study. Asian Journal of Information Science and Technology, $5(1), 15-22$.

[8] Das, P., \& Choudhury, B. K. (2014).Collection Management Practices in Emerging Web Scenario : A study of Selected university Libraries in Odisha. International Research: Journal of Library \& Information Science,4(2),253-266.

[9] Sahu,M . K. (2013) . Skill, Competencies and Current Practice of Library Professionals in Engineering College Odisha: Analytical Study. International Research: Journal of Library \& Information Science,3(4),631-647.

[10] Sahu, M. K ., \& Mahapatra, R. K. (2011). State of Digital Library Initiatives in Engineering \& Technology College Libraries affiliated to BPUT, Orissa: An Empirical approach.VSRD-TNIJ,2(9),449-461.

[11] Sahu, N. K., \& Basa, S. S. (2009). Usage of Electronic information resources and Services among the students of Seemanta Engineering College, Jharpokhoria, Orissa : A Study. IJISS,3(2), 17-22.

[12] Srivastava, B., \& Kumar, S. (2018). Usage and Impact of Science Direct Material Science Package in a Material Science Library. DESIDOC Journal of Library and Information Technology,38(1),21-26. DOI : 10.14429/djlit.38.1.12124

[13] Santhi, J., \& Jeyachitra,S. (2014). Use and Impact of E-Resources at the Urumudhanalakshmi college, Trichirapali. IJSR-International Journal of Scientific Research,3(2),235-237.

[14] Kumar, M.P., \& Bhandi,M.K. (2016).Use and Impact of E-Resources among Faculty and postgraduate Students in Selected Nursing College Libraries in Mangalore, Kranataka. Indian Journal of Library and Information Science,10(1),22-26.

[15] Vanaja,E.L. (2017).Usage and Impact of e-Resources in Special Libraries : Attitudes, Aspiration and problems of the Librarians. PEARL- a journal of Library and Information Science,11(2),143-147. DOI: 10.5958/0975-6922.2017.00019.5

[16] Badhusa, K. N., \& Natarajan, R. (2014).Use and Impact of E-Resources Management in Selected Engineering Colleges in Ramanathapuram District. e- Library science Research journal,2(11),1-10. 
[17] Hiller, S. (2002). The impact of Information Technology and Online Library Resources on Research, teaching, and Library at the university of Washington. Performance Measurement and Metrics,3(3),134-139. http://dx.doi.org/10.1108/14678040210454923.

[18] Pulm, T., Franklin, B., Kyrillidou, M., Roebuck, G., \& Davis, M. (2012).Measuring the Impact of Networked electronic Resources: Developing an Assessment Infrastructure for Libraries, State, and other Types of Consortia. Performance Measurement and Metrics,11(2),184-198. http://dx.doi.org/10.1108/14678041011064098

[19] Abinew, A.A. \& Vuda, S. (2013) A case study of acceptance and use of electronic library services in universities based on SO-UTAUT model. International Journal of Innovative Research in Computer and Communication Engineering, 1(4), 903-910. Retrieved from:

[20] http://ijircce.com/upload/2013/june/17_A\%20Case\%20Study.pdf

[21] Tenopir, C. (2003). Use and Users of Electronic library Resources: An Overview and Analysis of Recent Research Studies, Washington, D. C: Council on Library and Information Resources. Retrieved from https://clir.org/wpcontent/uploads/sites/6/pub120.pdf 